${ }^{22}$ L'Hermitte F, Fardeau M, Chedru F, Mallecourt J. Polyneuropathy after perhexiline maleate therapy. Br Med f 1976;i:1256.

${ }^{23}$ Singlas E, Goujet MA, Simon P. Pharmacokinetics of perhexiline maleate in anginal patients with and without peripheral neuropathy. Eur $\mathcal{f}$ Clin Pharmacol 1978;14:195-201.

${ }^{24}$ Mahgoub A, Idle JR, Dring LG, Lancaster R, Smith RL. Polymorphic hydroxylation of debrisoquine in man. Lancet 1977;ii:584-6.

${ }^{25}$ Sloan TP, Mahgoub A, Lancaster R, Idle JR, Smith RL. Polymorphism of carbon oxidation of drugs and clinical implications. $\mathrm{Br}$ Med 7 1978;ii: 655-7.

${ }^{26}$ Price Evans DA, Mahgoub A, Sloan TP, Idle JR, Smith RL. A family and population study of the genetic polymorphism of debrisoquine oxidation in a British white population. F Med Genet 1980;17:102-5.

27 Sloan TP, Idle JR, Smith RL. Influence of $\mathrm{D}^{\mathrm{H}} / \mathrm{D}^{\mathrm{L}}$ alleles regulating debrisoquine oxidation on phenytoin hydroxylation. Clin Pharmacol Ther $1981 ; 29: 493-7$.

${ }^{28}$ Shah RR, Oates NS, Idle JR, Smith RL. Genetic impairment of phenformin metabolism. Lancet $1980 ; 1: 1147$.

${ }^{29}$ Ritchie JC, Sloan TP, Idle JR, Smith RL. Toxicological implications of polymorphic drug metabolism. In: Environmental chemicals, enzyme function and human disease. (Ciba Foundation Symposium 76). Amsterdam; Excerpta Medica, 1980:219-44.

30 Williams RL, Mamelok RD. Hepatic disease and drug pharmacokinetics. Clin Pharmacokinet 1980;5:528-47.

${ }^{31}$ Weiner M, Chenkin T, Burns JJ. Observations on the metabolic transformation and effects of phenylbutazone in subjects with hepatic disease. Am 7 Med Sci 1954 ;228:36-9.
32 Brodie BB, Burns JJ, Weiner M. Metabolism of drugs in subjects with Laennec's cirrhosis. Med Exp 1959;1:290-2.

${ }^{33}$ Nelson E. Rate of metabolism of tolbutamide in test subjects with liver disease or with impaired renal function. Am f Med Sci 1964 ;248:657-9.

${ }^{34}$ Oldershausen HF von, Held $\mathrm{H}$, Remmer $\mathrm{H}$. Der Abbau von Pentabarbital bei leberschaden. Klin Wochenschr 1970;48:565-7.

${ }^{35}$ Levi AJ, Sherlock S, Walker D. Phenylbutazone and isoniazid metabolism in patients with liver disease in relation to previous drug therapy. Lancet $1968 ; \mathrm{i}: 1275-9$.

${ }^{36}$ Held H, Oldershausen HF von. Zur Pharmakokinetik von Meprobamat bei chronischen Hepatopathien und Arzneimittelsucht. Klin Wochenschr $1969 ; 47: 78-80$

37 Anonymous. Drug metabolism in disease. Lancet $1974 ; \mathrm{i}: 790-1$.

${ }^{38}$ Pollet S, Hauw JJ, Escourolle R, Baumann N. Peripheral-nerve lipid abnormalities in patients on perhexiline maleate. Lancet 1977;i:1258.

39 Idle JR, Mahgoub A, Lancaster R, Smith RL. Hypotensive response to debrisoquine and hydroxylation phenotype. Life Sci 1978;22:979-84.

${ }^{40}$ Idle JR, Oates NS, Shah RR, Smith RL. Is there a genetic predisposition to phenformin-induced lactic acidosis? Br $\mathcal{F}$ Clin Pharmacol $1981 ; 11$ : 418P-9P.

41 Oates NS, Shah RR, Idle JR, Smith RL. Phenformin-induced lactic acidosis associated with impaired debrisoquine hydroxylation. Lancet $1981 ; \mathrm{i}: 837-8$.

42 Bertilsson L, Mellström B, Sjöqvist F, Märtensson B, Äsberg M. Slow hydroxylation of nortriptyline and concomitant poor debrisoquine hydroxylation: Clinical implications. Lancet 1981 ; i :561-2.

(Accepted 6 October 1981)

\title{
Effects of alcohol and smoking on blood lead in middle-aged British men
}

\author{
A G SHAPER, S J POCOCK, MARY WALKER, C J WALE, BARBARA CLAYTON, H T DELVES, \\ LESLEY HINKS
}

\begin{abstract}
A survey of middle-aged men in 24 British towns showed a strong association between blood lead concentrations, alcohol consumption, and cigarette smoking. The association with alcohol persisted after age, social class, body mass index, cigarette smoking, water lead concentrations, and the town of residence had been taken into account. There was an independent but less pronounced association between cigarette smoking and blood lead concentrations after adjustment for the other factors. The possible mechanisms include a decreased excretion of lead due to alcohol-induced hepatic dysfunction and an increased lead intake from cigarette smoking.

These findings have implications for widespread measurement of blood lead concentrations in adults in the community and for all studies attempting to relate blood lead concentrations to environmental exposure.
\end{abstract}

\footnotetext{
Department of Clinical Epidemiology and General Practice, Royal Free Hospital School of Medicine, London NW3 2QG

A G SHAPER, FRCP, FRCPATH, professor of clinical epidemiology

S J POCOCK, MSC, PHD, senior lecturer in medical statistics MARY WALKER, SRN, SCM, research administrator

C J WALE, statistical technician
}

Department of Chemical Pathology and Human Metabolism, University of Southampton, Southampton SO9 4XY

BARBARA E CLAYTON, FRCP, FRCPATH, professor of chemical pathology and human metabolism

H T DELVES, PHD, FRSC, honorary senior lecturer in chemical pathology LESLEY HINKS, FIMLS, senior medical laboratory scientific officer

\section{Introduction}

The British Regional Heart Study seeks to explain the substantial geographical variations in cardiovascular mortality in Great Britain by evaluating the role of environmental, socioeconomic, and personal risk factors. The role of water quality is of particular interest, and analysis of data collected in the study has recently shown that cardiovascular mortality is about $10 \%$ higher in areas with very soft water than in areas with medium-hard water, after appropriate adjustments have been made for other factors such as climate and socioeconomic circumstances. ${ }^{1}$ The mechanism by which soft water is associated with a higher cardiovascular mortality is uncertain but one of the possibilities considered was the increased water lead concentrations seen in many soft, acid waters. ${ }^{2}{ }^{3}$

The Regional Heart Study includes a clinical survey of middle-aged men in 24 British towns, carried out to determine the distribution of established or possible risk factors for cardiovascular disease, to examine their interrelationships and to initiate a long-term prospective study of cardiovascular disease based on these findings. ${ }^{4}$ The survey has included the measurement of blood lead concentrations, and this report describes some relationships observed between blood lead concentration, cigarette smoking, and alcohol consumption in these middle-aged men.

\section{Subjects and methods}

The British Regional Heart Study covers 7735 men aged 40-59 years randomly selected from the age-sex registers of representative general practices in 24 British towns. The criteria for selecting the towns, the general practices, and the subjects as well as the methods of data collection have been presented in a separate report. ${ }^{4}$ In brief, 
the 24 towns were primarily selected from those with populations of 50000 to 100000 (1971 census). They were chosen to represent the full range of cardiovascular disease mortality and included towns in all the major standard regions. The general practice selected in each town was required to have a social class distribution that reflected the social class distribution of the men of that town. Trained research nurses gave each man an extensive standard questionnaire that included questions on occupational history, smoking habits, and alcohol consumption.

Smoking habits were recorded as follows: never smoked, excigarette smoker, pipe/cigar only, pipe/cigar smokers who were ex-cigarette smokers, and current cigarette smokers at four levels (1-19, 20, 21-39, $\geqslant 40 /$ day). Alcohol consumption was recorded using questions on frequency, quantity, and type similar to those used in the General Household Survey. ${ }^{5}$ Eight drinking categories were used: non-drinkers, men drinking on special occasions or $1-2 /$ month, men drinking at weekends (1-2, 3-6, or $>6$ drinks per day), and men drinking daily or on most days (1-2, 3-6, and $>6$ drinks per day). A "drink" was defined as half a pint of beer, a glass of wine, or a tot of spirits. To determine social class the longest held occupation of each man was coded and the men were then classified within one of the six social classes of the Office of Population Censuses and Surveys.

Blood lead analyses were carried out on 7378 men (95\%) using flame microsampling atomic absorption spectroscopy ${ }^{6}$ with minor modifications to the original procedure: sample volumes were reduced to $6 \mu \mathrm{l}$; the wavelength was $217.0 \mathrm{~nm} ; \mathrm{Al}_{2} \mathrm{O}_{3}$ absorption tubes were used; and the absorption signals were integrated. The missing samples were mainly accounted for by clotting problems in the specimens. To ensure comparability of blood-lead results over the two years of this study, a strict internal quality control protocol was maintained and the quality of the analyses was assessed by participation in national and international quality assurance programmes. Since blood lead concentrations follow a log-normal distribution, the results were expressed in terms of geometric means.

\section{Results and comment}

Fig 1 shows the geometric mean blood lead concentrations with $95 \%$ confidence limits for men in each drinking category. Men drinking three or more drinks daily or on most days showed a pronounced increase in mean blood lead concentrations. For the men drinking more than six drinks daily ( $11 \%$ of all men) the mean blood lead was $30 \%$ higher than that seen in non-drinkers and occasional drinkers. There was also evidence of smaller increases in blood lead concentration for light daily drinkers and for moderate and heavy weekend drinkers.

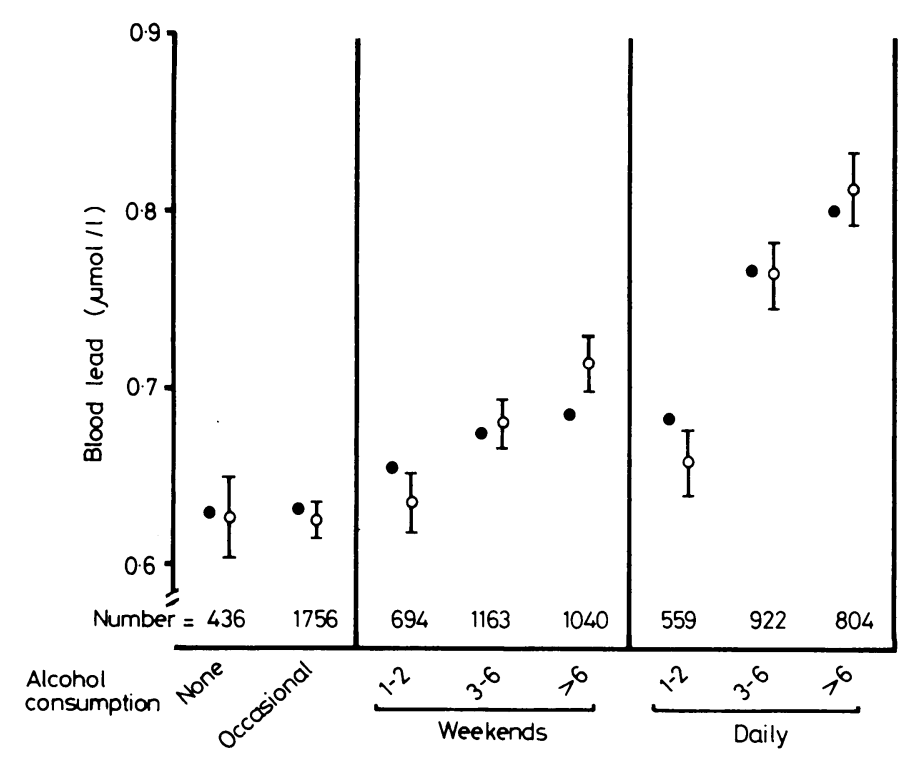

FIG 1-Blood lead concentration in middle-aged British men by alcohol consumption. $O=$ Geometric mean and $95 \%$ confidence limits. 0 Geometric mean adjusted for smoking status, social class, and town of residence. (Occasional $=$ special occasion or $1-2 /$ month.)

Conversion: SI to traditional units-Lead: $1 \mu \mathrm{mol} / 1 \approx 20 \cdot 1 \mu \mathrm{g} / 100 \mathrm{ml}$.

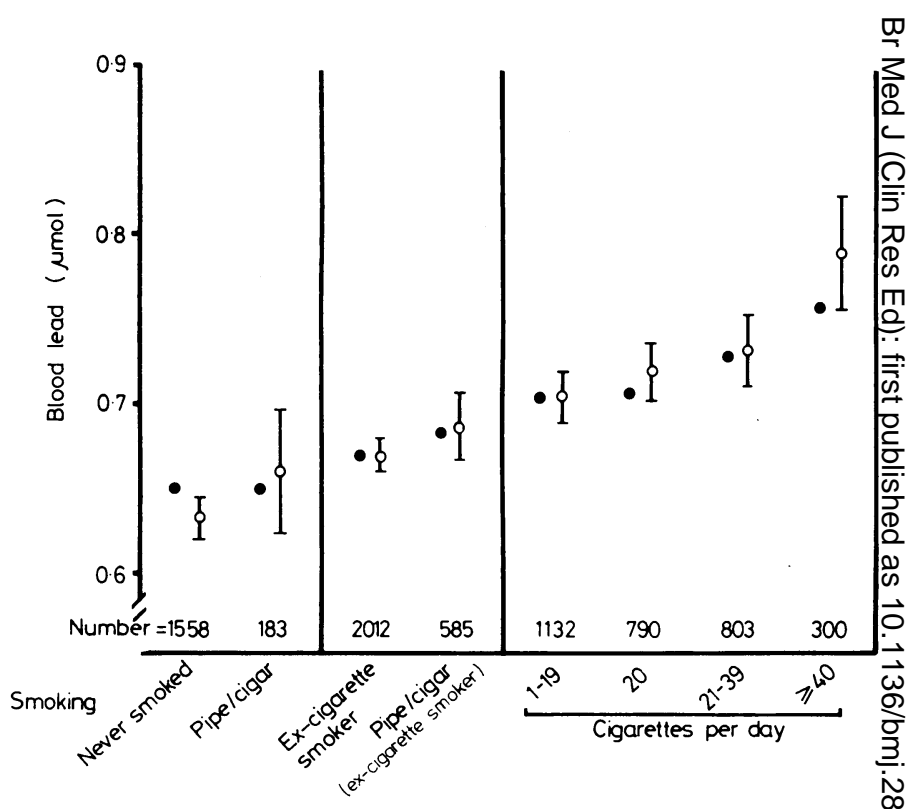

FIG 2-Blood lead concentration in middle-aged British men by smoking. ${ }^{+}$ status. $\mathrm{O}=$ Geometric mean and $95 \%$ confidence limits. $\bullet=$ Geometric $\mathcal{W}^{\circ}$ mean adjusted for alcohol intake, social class, and town of residence.

Fig 2 shows the mean blood lead concentrations by smoking? categories. Those who had never smoked and those smoking only pipesw or cigars showed the lowest blood lead concentrations. There was a small but significant increase in blood lead concentration in ex-cigarette smokers and in ex-cigarette smokers currently smoking? pipes and cigars. For all categories of cigarette smoking the mean blood lead concentration was increased, and in heavy smokers $(\geqslant 40 /$ day) it was $25 \%$ higher than in those who had never smoked. $\bullet$ The combined effects of smoking and drinking were shown by compar-N ing 229 men who smoked more than 20 cigarettes a day and drank more than 6 drinks a day with 423 men who had never smoked ando who were occasional drinkers. The mean blood lead concentrations were 0.85 and $0.59 \mu \mathrm{mol} / 1(17.6$ and $12.2 \mu \mathrm{g} / 100 \mathrm{ml})$ respectively, $\overline{0}$ reflecting an increase of some $44 \%$ that was apparently produced by heavy smoking and drinking.

It is important to allow for other environmental and personal factors $\Rightarrow$ which might affect the blood lead concentration. Manual workers had윽 a higher geometric mean blood lead concentration than non-manual workers $(0.70$ and $0.67 \mu \mathrm{mol} / 1(14.5$ and $13.9 \mu \mathrm{g} / 100 \mathrm{ml})$ respectively) and there were considerable differences between towns in geometricmean blood lead concentrations (range 0.51 to $0.94 \mu \mathrm{mol} / 1$ (10.6-19.5 $\mu \mathrm{g} / 100 \mathrm{ml})$ ). We therefore used analysis of covariance to adjust the mean blood lead concentration in the several drinking groups for:smoking status, social class, and the town of residence. The resulting adjusted mean blood lead values are also shown in fig 1 . Similarly, for each smoking group the mean blood lead level was adjusted for drinking status, social class, and town of residence (fig 2).

These adjustments confirmed the simple (univariate) association? between alcohol intake and blood lead concentration. Furthermore, N this association was shown separately for each smoking category, each social class, and each town. The same applied to the associationo between cigarette smoking and blood lead concentration. Adjustment did, however, make some difference to the pattern of association. For $\tilde{O}^{-}$ example, fig 1 shows that those men drinking one or two drinks daily had an increased adjusted mean blood lead concentration. This was $\sigma$ probably because drinking at this level is more common in areas of higher social class with more non-smokers and in towns with lowere blood lead concentrations. In fig 2 the adjusted blood lead concentration was reduced in men smoking 40 or more cigarettes a day. This was probably because this group contained more heavy drinkers, more $\frac{0}{0}$ manual workers, and more towns with higher blood lead concentrations. The overall effect of the adjustments was to show that the associations@ of smoking and drinking with blood lead could not be explained away by these other factors.

During the clinical survey tap water samples were collected from the homes of 941 men $\left(12^{\circ} \%\right)$, and lead concentrations were measuredô by the Water Research Centre, Medmenham. Fifty-three $(5.6 \%)$ of the "first-draw" samples and $28(3 \%)$ of the daytime samples containedō. more than $100 \mu \mathrm{g} / \mathrm{l}$, the WHO recommended limit for lead in water,? 
and $12(1.3 \%)$ first-draw samples were above the WHO first-draw limit of $300 \mu \mathrm{g} / 1$. There is a well-established relationship between water lead and blood lead concentrations, ${ }^{7}$ and we therefore had to consider whether the associations seen with alcohol and smoking could have been attributed to variations in water lead concentration. In those men living in houses with low levels of water lead $(<10 \mu \mathrm{g} / \mathrm{l}$ first draw) there was still a strong association between alcohol intake and blood lead concentration. In the smaller group of men living in houses with higher water lead levels, the same pattern of relationship between alcohol intake and blood lead concentration existed. These findings suggested that the relationship between alcohol intake and blood lead concentration was independent of water lead levels. Similarly, the effect of cigarette smoking on blood lead concentration was independent of water lead levels. Age and body mass index (weight/height ${ }^{2}$ ) showed no association with blood lead.

The European Community directive $77 / 312$ requires that in certain statutory surveys no more than $2_{\circ}^{\circ}$ of any group surveyed should have blood lead concentrations above $35 \mu \mathrm{g} / 100 \mathrm{ml}(1 \cdot 7 \mu \mathrm{mol} / \mathrm{l}){ }^{8}$ In this study 74 men $(1 \cdot 0 \%)$ had blood lead levels greater than $1.7 \mu \mathrm{mol} / 1$. In men drinking more than six drinks daily $2 \cdot 1 \%(17 / 804)$ had blood lead concentrations of over $1.7 \mu \mathrm{mol} / 1$ compared with $0.8 \%(17 / 2192)$ of those drinking occasionally or not at all.

\section{Discussion}

There is considerable interest in the measurement of blood lead concentrations in the community, as evidence has been brought forward to support relationships between the body burden of lead and various health problems. ${ }^{9}$ This evidence concerns in particular the intellectual functioning and behaviour patterns of children, ${ }^{10} 11$ but it has also been suggested that increased intakes of lead may be associated with renal disease ${ }^{12}$ and hypertension. ${ }^{13} \mathrm{~A}$ recent European Community directive requires that all member states undertake screening campaigns for lead in various population groups and provides reference levels which must be applied to the results of such surveys. ${ }^{8}$ Blood lead concentrations in the community are recognised as being determined in the main by dietary intake (including drinking water) and also by environmental sources such as lead in air derived from petrol. ${ }^{14}$ The relative contributions of these sources is disputed but a recent review concluded that lead emitted by traffic and directly inhaled was not a major source of pollution. ${ }^{9}$ Nevertheless, the indirect contribution of such lead (via food and dust) remains to be adequately assessed.

Our findings suggest that both alcohol and cigarette smoking are making significant independent contributions to blood lead concentrations in middle-aged men in British towns, and there are several ways in which this might be explained. A direct increase in lead intake from cigarettes and alcohol may be responsible. Cigarettes contain varying amounts of lead and smoking 20 a day has been estimated to result in the inhalation of $1-5 \mu \mathrm{g}$ of lead..$^{15}$ Nevertheless, the lead contribution from cigarette smoking is not considered to be great enough to increase the blood lead concentration above that found in nonsmokers. ${ }^{16}$ In some industrial studies higher blood lead concentrations in smokers have been attributed to the transfer of lead from the fingers to the cigarette. ${ }^{17}$ Our study shows that cigarette smoking does make a significant independent contribution to the blood lead concentration but less than that associated with alcohol intake. The increased blood lead values in ex-cigarette smokers seem unusual but may be accounted for by the wellknown propensity of many cigarette smokers to claim that they have given up smoking when they have not in fact done so. ${ }^{18}$

The very limited information available in the United Kingdom on the lead content of alcoholic drinks ${ }^{19}$ indicates that wine has a mean lead content of $0.12 \mathrm{mg} / \mathrm{kg}$ and spirits, beer, and cider a mean content of $0.02 \mathrm{mg} / \mathrm{kg}$. The recommended limit for lead in all alcoholic drinks is $0.2 \mathrm{mg} / \mathrm{kg} .{ }^{20}$ More than half $(56 \%)$ of the men in the Regional Heart Study drank only beer, a further $13 \%$ drank beer and spirits, and $11 \%$ drank spirits only. Seven per cent drank only wine or sherry, or both. When the blood lead data in this study were examined separately for men who drank beer only, those drinking spirits, and those drinking wine or sherry only, the pattern of relationships seen in fig 1 was similar for all three groups. This suggests that the increased blood lead concentration seen with increasing alcohol intake is not due to a specific beverage, for example, wine, and is thus probably not due to an increased intake of lead.

Alcohol in the diet may lead to increased absorption of lead from the bowel. There is no direct evidence for this in man, and animal studies suggest either that such an effect is very limited ${ }^{21}$ or that alcohol actually diminishes the absorption of lead from the gut. ${ }^{22}$ The metabolism of lead and calcium are closely related and calcium appears to reduce the intestinal absorption of lead. ${ }^{16}$ In Britain there are both individual and regional differences in the dietary intakes of calcium. ${ }^{23}{ }^{24}$ There are also considerable variations between regions and towns in the content of calcium in the drinking water, ${ }^{1}$ and it has been suggested that the availability of lead in hard water is low. In subjects receiving similar concentrations of lead in drinking water the blood lead concentrations are apparently lower in those living in hard water areas compared with those living in soft water areas. ${ }^{25}$ Since we have no information on total calcium intakes in individuals, we can approach this question only indirectly. In each of the 24 towns studied, towns presumably differing in their overall dietary patterns and certainly differing in their water calcium content, the positive effect of alcohol on blood lead concentration was evident and the same was true for the effect of cigarette smoking. Indirectly, this suggests that the effects of alcohol and tobacco are independent of any effect which dietary calcium may have. This is not to say that dietary calcium or, specifically, water calcium may not be affecting the blood lead concentration but that we cannot answer that question from these data.

Lead is excreted mainly through the kidney by glomerular filtration, ${ }^{26}$ and there is evidence from animal studies that it is also excreted in the liver, mainly in the bile. ${ }^{27-29}$ In the Regional Heart Study data there is no suggestion from the serum urea or creatinine concentrations that alcohol intake at any level adversely affects renal function. There is, however, strong evidence of hepatic dysfunction, as shown by increased activities of $\gamma$-glutamyl transferase and aspartate aminotransferase with increasing intake of alcohol (unpublished data). If the liver is an important site of lead excretion then moderate to heavy alcohol intake on a daily basis may affect hepatic ability to excrete lead, resulting in increased blood lead concentrations.

Danish workers have suggested that lead accumulates in the liver in patients with severely impaired hepatic function (cirrhosis) and that acute liver damage induced by alcohol in these patients causes a release of lead from the liver to the blood. ${ }^{30}$ These findings are supported by French workers who have studied several groups of patients with advanced liver disease. ${ }^{31}$ The highest blood lead concentrations were found in those still drinking heavily ( 1 to 4 litres of wine daily with an estimated lead content of $0.25 \pm 0.15 \mathrm{mg} / \mathrm{l})$, but all groups had mean blood lead concentrations (by the Delves's method) ${ }^{6}$ higher than those seen in the men in any of our 24 towns. Our data relate to "normal" subjects who are not considered to be suffering from alcoholism or cirrhosis, and we must therefore consider the possibility of lead metabolism being affected at socially acceptable levels of alcohol intake.

The possibility of a relationship between blood lead concentration and the amount of alcohol ingested has not previously been carefully examined, and most studies have been performed in industrial workers and have been only indirectly concerned with alcohol intake ${ }^{32} 33$ or relate to alcoholics with or without hepatic cirrhosis. ${ }^{30}$ Our findings suggest that alcohol may significantly change blood lead concentrations, particularly in adults drinking moderately or heavily every day. This phenomenon, together with the independent contribution to blood lead concentration from cigarette smoking, must be taken into account in assessing environmental exposure to lead. There is always the possibility that some confounding variable, other than those such as social class, concentrations of lead in drinking water, and the town of residence, has not been measured. Such an alternative explanation seems unlikely, given the strength of 
the associations for both alcohol and cigarette smoking and the consistency with which the same pattern was seen in each of the 24 towns in this study.

The British Regional Heart Study is supported by a programme grant from the Medical Research Council. The work of the Water Research Centre is supported by the Department of the Environment. Biochemical estimations in this study, other than lead, were carried out at the Wolfson Research Laboratories, Queen Elizabeth Hospital, Birmingham (Professor T Whitehead), under a programme supported by the DHSS. We are grateful to Mrs Sylvia Diaper and Mrs June Wilson (Southampton) and to Mr John Mitchell (the Hospital for Sick Children, Great Ormond Street, London) for technical help and Miss Deborah Davis (Royal Free Hospital) for preliminary analysis of the data.

Requests for reprints should be addressed to Professor A G Shaper.

ADDENDUM-A recent Danish study in 40-year-old men and women substantially supports our British findings. Blood lead concentration increased with increasing alcohol consumption, independently of smoking habits. The independent effects of smoking were less significant. ${ }^{34}$

\section{References}

1 Pocock SJ, Shaper AG, Cook DG, et al. British Regional Heart Study geographic variations in cardiovascular mortality, and the role of water quality. $B r$ Med $\mathcal{F} 1980 ; 280: 1243-9$.

2 Department of the Environment. Lead in Drinking Water; a survey in Great Britain, 1975-76. London: HMSO, 1977. (DOE Clinical Unit on Environmental Pollution, Pollution Paper N 12.)

3 Pocock SJ. Factors influencing household water lead: a national survey. Arch Env Health 1980;35:45-51.

+ Shaper AG, Pocock SJ, Walker M, Cohen NM, Wale CJ, Thomson AG. British Regional Heart Study : cardiovascular risk factors in middle-aged men in 24 towns. Br Med $\mathcal{F} 1981 ; 283: 179-86$.

${ }^{5}$ Office of Population Censuses and Surveys. The General Household Survey, 1978. London: HMSO, 1980.

${ }^{6}$ Delves HT. A micro-sampling method for the rapid determination of lead in blood by atomic absorption spectrophotometry. Analyst 1970;95: 431-8.

${ }^{7}$ Moore MR, Meredith PA, Campbell BS, Goldberg A, Pocock SJ. Contribution of lead in drinking water to blood lead. Lancet 1977; ii : 661-2.

${ }^{8}$ Department of the Environment. Central Directorate on Environmental Pollution. European screening programme for lead: UK results for 19791980. London, HMSO, 1981. (Pollution Report No 10.)

9 DHSS Working Party on Lead in the Environment. Lead and Health. London: HMSO, 1980.

10 Needleman HL, Gunnoe C, Leviton A, et al. Psychological performance of children with elevated lead levels. N Engl f Med 1979;300:689-95.

11 Yule W, Lansdown R, Millar IB, Urbanowicz MA. The relationship between blood lead concentrations, intelligence and attainment in a school population: a pilot study. Develop Med Child Neurol $1981 ; 23: 3$ 567-76.

12 Campbell BC, Beattie AD, Moore MR, Goldberg A, Reid AG. Renal insufficiency associated with excessive lead exposure. $\mathrm{Br}$ Med f 1977; 482-5.

13 Beevers DG, Erskine E, Robertson M, et al. Blood lead and hypertension. $\overline{\bar{J}}$ Lancet 1976;ii:1-3.

14 Gloag D. Sources of lead pollution. Br Med F 1981 ;282:41-4.

15 World Health Organisation. Environmental health criteria: 3 lead. Geneva : WHO, 1977.

16 Waldron HA. Lead. In: Waldron HA, ed. Metals in the environment. London: Academic Press, 1980.

17 Tola S, Nordman CH. Smoking and blood lead concentrations in lead- $\stackrel{\vec{S}}{\oplus}$ exposed workers and an unexposed population. Environ Res 1977;13: 250-5.

18 Sillett RW, Wilson MB, Malcolm RE, Ball KP. Deception among smokers. $\overline{\bar{\omega}}$ Br Med 7 1978; ii:1185-6.

19 Ministry of Agriculture, Fisheries and Food. Working Party on the monitoring of foodstuffs for heavy metals. Fifth report. Survey of lead in food: first supplementary report. London: HMSO, 1975.

${ }^{20}$ Ministry of Agriculture, Fisheries and Food. Food Additives and con- $\overrightarrow{0}$ taminants review of the lead in food regulations 1961. London: HMSO, 1975.

21 Mahaffey KR, Goyer RA, Wilson MH. Influence of ethanol ingestion on lead toxicity in rats fed isocaloric diets. Arch Environ Health $1974 ; 28$ :O 217-22.

22 Barton JC, Conrad ME. Effects of ethanol on the absorption and retentioniN of lead. Proceedings of the Society for Experimental Biology and Medicine. $\stackrel{\infty}{\perp}$ $1978 ; 159: 213-8$

${ }^{2} 3$ Bingham S, McNeil NI, Cummings JH. The diets of individuals: a study $\vec{\omega}$ of a randomly chosen cross-section of British adults in a Cambridgeshire $\vec{N}$

village. Br $\mathcal{F}$ Nutrition $1981 ; 45: 23-5$.
${ }^{24}$ Ministry of Agriculture, Fisheries and Food. Household food consumption and expenditure 1979. Annual report of the national food survey committee.
London: HMSO, 1981 .

25 Thomas HF, Elwood PC, Toothill C, Morton M. Blood and water leadW in a hard water area. Lancet $1981 ; \mathrm{i}: 1047-8$.

26 Vostal J. In Proceedings of the 15th International Congress of Occupational Health. Geneva: International Labour Office, 1966:61-4.

27 Blaxter KI, Cowie A T. Excretion of lead in the bile. Nature 1946;157:588.

${ }^{28}$ Castellino NO, Lamaana P, Greco B. Biliary excretion of lead in the rat.

Br $\mathcal{F}$ Indus Med $1966 ; 23: 237-9$.
${ }^{29}$ Cikrt M. Biliary excretion of ${ }^{203} \mathrm{Hg},{ }^{64} \mathrm{Ca},{ }^{52} \mathrm{Mn}$ and ${ }^{210} \mathrm{~Pb}$ in the rat. $B r \underset{\mathcal{O}}{\overrightarrow{\mathrm{O}}}$ Industr Med $1972 ; 29: 74-80$.

${ }^{30}$ Magid E, Hilden M. Elevated levels of blood lead in alcoholic liver disease. Int Arch Occup Hlth 1975;35:61-5.

31 Vives JF, Beller H, Lapinski $\mathrm{H}$, et al. Alcoolisme chronique et intoxication saturnine. Gastroenterol Clin Biol 1980;4:119-22.

32 Cramer K. Predisposing factors for lead poisoning. Acta Med Scand 1966 suppl 445:56-9.

${ }^{33}$ Flindt MLH, Kerg E, Walsh DB. Blood lead and erythrocyte and 8-으 aminolaevulinic acid dehydratase levels in Manchester taxi drivers. $\overline{0}$ Br F Industr Med 1976;33:79-84.

34 Grandjean $\mathrm{P}$, Olsen NB, Hollnagel $\mathrm{H}$. Influence of smoking and alcoholconsumption on blood lead levels. Int Arch Occup Environ Health 1981 48:391-7.

(Accepted 20 November 1981)
ONE HUNDRED YEARS AGO The death of Garibaldi, the funeral ceremonies at Caprera, and the honours which await his memory, continue to be the all-absorbing topics of conversation, not only in Rome but throughout Italy. The impression caused by the unexpected news of his death fully equalled that which the nation manifested for the loss of Victor Emmanuel. The Italians are true hero-worshippers and never try to hide the emotions, which might possibly be felt as deeply, but would certainly not be shown as openly, by us at great national bereavements. For the last ten years nearly, the hero of the Italian nation has been a helpless cripple from rheumatism and rheumatoid arthritis, caused by the innumerable hardships and great exposure attendant on his adventurous and glorious campaigns. As long ago as 1875 it was almost impossible for him to walk, and the succeeding years only aggravated his state. When he crossed to Genoa and Milan, rather more than a year ago, he was always carried about recumbent, and was scarcely able even to raise a hand to salute the applauding crowds. His island home could not improve such a condition, and it is known that he suffered much pain. During the last winter, he had been greatly troubled with bronchitis; and, though the trip to Naples and residence at Pozzuol were of service to him, and enabled him to go to Palermo to the celebration of the Sicilian Vespers, it was noticed that his strengthN had greatly failed. Not long after his return to Caprera, the bronchitisN became worse again; his appetite entirely failed; and it was said that he was unable to swallow fluids even for three days before his death. Indeed, the medical certificate signed by Dr Albanese state that the cause of death was paralysis of the pharynx! No necropsyd seems to have been made. The family, yielding to the desire of many ${ }^{+}$ friends, reluctantly gave up the idea of cremating the body, as directed by himself; they had it embalmed, and have buried it in the meantime at Caprera, until the representatives of the nation settle where its finab resting-place shall be. Owing to the very natural hesitation of the्ठ family before finally deciding not to obey the expressed wish of Garibaldi, the embalming was too long deferred, and did not prove a success. Nothing, however, can justify the nauseating details as to the appearance of the body when lying in state, which several Italia newspapers have published.-(British Medical fournal, 1882.) 